and delivery in an ambulance-do result in impaired academic performance among children at ordinary schools, it seems unlikely that they exert more than a small influence on the intellectual development of children exposed to them. The distributions of scores of affected children were unimodal (Tables VI and XI) and therefore provided no evidence of a substantial group of children whose development was greatly impaired; and there were only small differences in the mean scores of affected and unaffected sibs.

A previous analysis of the relation between obstetric complications and subnormal intelligence (an I.Q. below 75), based on the same obstetric data as the present analysis, revealed an association between educational subnormality and both precipitate labour and delivery in the absence of a qualified attendant (Barker, 1966). But neither of these complications seems to be associated with impaired performance within the normal range of intelligence.

The mean V.R. scores of children delivered instrumentally or by caesarean section were higher than those of the population and of their unaffected sibs. It seems reasonable to suppose that a child born by caesarean section may avoid cerebral damage sustained in a normal delivery; but it is difficult to explain the association between instrumental delivery and raised V.R. scores. The data are, however, too complex to justify the conclusion that instrumental delivery will improve school performance.

The finding that the mean V.R. score in the population declines with increasing birth rank (Table II) confirms numerous previous observations of the negative correlation between fraternity size and measured intelligence. But this inquiry has also shown that within fraternities there is an average fall of 1.0 in V.R. score with each unit increase in birth order.

\section{Summary}

Birth records of 50,000 children were linked with records of school performance at the age of 11 . Twins and triplets showed marked impairment, and were excluded from this study. The verbal reasoning (V.R.) scores of single-born children exposed to obstetric complications were compared with those of the population and of their sibs. The results suggested that impaired performance was associated with only five of the obstetric complications studied: a short gestation period, a prolonged gestation period, toxaemia, occipito-posterior presentation, and delivery in an ambulance. In no case was the impairment very marked. Within fraternities there was a fall in average V.R. score with increasing birth rank.

It is a pleasure to thank Dr. E. L. M. Millar, Medical Officer of Health for Birmingham, and Sir Lionel Russell, Chief Education Officer for Birmingham, for permission to transfer records in their departments on to magnetic tape, and Dr. E. D. Acheson for lending a programme for converting names into the Hogben number. Computer Services, Birmingham, made their Univac 1107 available on generous terms ; and we are particularly grateful to $\mathrm{Mr}$. R. J. Milne for advice and for creating the tape files.

\section{REFERENCES}

Barker, D. J. P. (1966) Brt. 7. prev. soc. Med., 20, 58

Charles, E. (1951). Brit. F. soc. Med., 5, 41.

Dale, M. H. (1966). Practitioner, 196, 430 .

Hogben, L., Johnstone, M. M., and Cross, K. W. (1948). Brit. med. Ұ., 1,632 .

Mehrotra, S. N., and Maxwell, J. (1949). Popul. Stud., 3, 295.

Sandon, F. (1957). ₹. roy. Statist. Soc., Series A, 120, 440.

\title{
Paraproteins, Benign or Malignant?
}

\author{
J. R. HOBBS,* M.D., M.R.C.P., M.C.PATH.
}

Paraproteins are those serum proteins which on electrophoresis are found to run as an abnormal narrow band between the positions occupied by the inter- $\alpha$ and post- $\gamma$ protein fractions. Once it is confirmed that the paraprotein contains a heavy chain or a light chain, or both, of one class only-that is, a monoclonal immunoglobulin or fragment thereof-it may be assumed that it has come from a single clone of cells within the reticuloendothelial system. The question then remains, will this "monoclone" behave in a malignant fashion-invading bone (myelomatosis), lymphoid tissue (lymphomata), or the blood stream (leukaemia) - or will it, like a benign tumour, strike a balance with its neighbouring tissues and cause no harm to the patient ?

Though much work (well reviewed by Hällén, 1966) has dealt with both malignant and benign conditions, less is known about the intermediate diseases owing to inadequate investigation during life or at necropsy. The present study includes 304 patients followed up to the time when a diagnosis of malignant disease was established or for at least three years. Prospective examination of fresh serum and urine from every patient has shown findings of prognostic value.

\section{Investigation of Paraproteins}

\section{Serum}

Serum was separated at $37^{\circ}$ C. to avoid missing cryoproteins and then electrophoresed on cellulose acetate. False
$M$ bands due to fibrinogen or old or uraemic serum were excluded (Hobbs, 1966a).

The level of $M$ protein was estimated as a percentage of the total uptake of amidoschwarz $10 \mathrm{~B}$ under standard conditions (Hobbs, 1965), great care being taken always to load the strip within a linear range, often set by the narrow bands of paraprotein. Strips were often run with decreasing applications until the percentage became constant. Usually no attempt was made to simulate peaks or subtract any underlying proteinsvertical cuts were made down the peaks. In this way reproducibility of $\pm 2 \%$ was achieved. From the total protein by a biuret method (suitably diluted for high values) using Armour bovine albumin standard the percentage of paraprotein was converted to g. $/ 100 \mathrm{ml}$. in the case of $\gamma \mathrm{G}, \gamma \mathrm{A}$, and $\gamma \mathrm{D}$ (where the dye-binding and biuret colour compared to albumin is reliable to within $5 \%$ overall). As the biuret method underestimates $\gamma \mathrm{M}$-paraproteins by $12 \%$, the specific gravity gradient tube of Lowry and Hunter (1945) was used for determining the total protein in such cases. By the above technique pure isolated paraproteins calibrated by ultraviolet absorption could be added to normal serum and recovered with an absolute accuracy of $\pm 0.2 \mathrm{~g} . / 100 \mathrm{ml}$.

By using our own monospecific rabbit antisera the presence of the paraprotein was confirmed by immunoelectrophoresis as an $M$ bow of enly one type of heavy or light chain, or both.

\footnotetext{
* Lecturer in Chemical Pathology, Postgraduate Medical School, London W.12.
} 
After personally examining over 800 positive and very many negative samples, I have yet to see an $M$ bow on immunoelectrophoresis that was not already apparent on cellulose acetate electrophoresis. Hence the latter method is a satisfactory screening test for paraproteins, though with paper electrophoresis small $M$ bands can readily be missed.

In every case serum immunoglobulin levels of classes other than the paraprotein were measured by a modified Mancini method (Hobbs and Maatela, 1967), as a percentage of the mean level for that class determined in 107 normal adults. In Fig. 2 the average is plotted-for example, a patient with myelomatosis producing only Bence Jones protein had $\gamma \mathrm{G}$ $44 \%, \gamma \mathrm{A} 50 \%$, and $\gamma \mathrm{M} 50 \%$ of mean adult normal; these results are plotted as "other immunoglobulins $48 \%$ mean normal."

$\gamma$ A-paraproteins have a shorter half-life (mean 6.4 days) than $\gamma$ G-paraproteins (mean 11.6 days) (Drivsholm, 1964); and for the same serum level have a faster turnover $(10.8 \%$ of the total pool) than $\gamma \mathrm{G}$-paraproteins ( $6 \%$ of the total pool). Thus simple serum levels do not allow a true comparison between $\gamma \mathrm{A}$ and $\gamma \mathrm{G}$ classes. In order better to compare such patients, all of the latter have arbitrarily been assumed to weigh $70 \mathrm{~kg}$., and to have a plasma volume of $50.7 \mathrm{ml} . / \mathrm{kg}$., and the plasma has been assumed to contain $71 \%$ of the total paraprotein pool -averages of available data in patients with myelomatosis (Gabuzda, 1962). Thus for a given serum level, $M$ g./ $100 \mathrm{ml}$. the total pool would be $\mathrm{M} / 100 \times 70 \times 50.7 \times 100 / 71=$ $50 \times \mathrm{M} \mathrm{g}$.; and for patients in equilibrium the average daily productions of $\gamma \mathrm{A}$ would be $10.8 \%$ of $50 \mathrm{M}=5.4 \times \mathrm{M}$ g. and of $\gamma \mathrm{G} 6 \%$ of $50 \mathrm{M}=3.0 \times \mathrm{M}$ g. In $\gamma \mathrm{M}$-paraproteinaemia an average daily turnover is $13.3 \%$ of the intravascular pool of $\gamma \mathrm{M}$-globulin (Barth et al., 1964), though these authors estimated the average plasma volume at only $45 \mathrm{ml} . / \mathrm{kg}$. Most of our patients were severely anaemic, so that an arbitrary plasma volume of $60 \mathrm{ml} . / \mathrm{kg}$. has been used, closer to that found in one patient of Gabuzda (1962) and in two patients of Olesen (1963). Thus, in equilibrium the daily production rate would be $\mathrm{M} / 100 \times 60 \times 70 \times 13.3 / 100=5.6 \times \mathrm{M}$ g.

Any loss of Bence Jones protein was measured in a 24-hour specimen of urine; it was corrected for the patient's body weight and added to the above productions (or used by itself for patients producing only Bence Jones protein) to obtain the approximate production of paraprotein in g. $/ 70 \mathrm{~kg}$. body weight/day. It is recognized that this value can be only approximate, since plasma and total body pools and the halflives of paraproteins all show individual variation (mostly less than $\pm 25 \%$ of the taken means) but this calculation is necessary to allow comparison of the different paraprotein classes in Fig. 2. Moreover, the large numbers of patients studied should help to overrule individual errors.

In Fig. 1 a value below the 2 S.D. lower limit of normal (for $\gamma \mathrm{G} 54 \%, \gamma \mathrm{A} 52 \%, \gamma \mathrm{M} 50 \%$ of mean adult levels) has been recorded as "other immunoglobulins subnormal." This is particularly relevant for $\gamma \mathrm{M}$-globulin-which was the only protein having subnormal levels in 21 patients who were later found to develop a malignant process. This would not be detected simply by assessing the electrophoretic $\gamma$-globulin other than the paraprotein, as Hällén (1966) did.

Where desired the molecular sizes of the paraproteins were confirmed by using thin-layer Sephadex G200 (Hobbs, 1966́a) or the ultracentrifuge.

\section{Urine}

Fresh urine (or preserved with toluene or azide) was examined in every case as follows. It was first cleared of bacteria by passage through a membrane filter with maximum pore size of $0.2 \mu$. Total protein was then measured by a biuret method on the redissolved precipitate from $10 \%$ trichloroacetic acid. Where significant, a 24-hour output was measured and the paraprotein content added into the total daily paraprotein production in Fig. 2 .

The urine was suitably concentrated (up to $\times 500$ within two hours by using Sartorius collodion shells attached to a vacuum pump) and electrophoresed alongside the patient's serum. Any $M$ bands were measured as a percentage of the total protein and confirmed and typed by immunoelectrophoresis. When desired, the size of the $M$ proteins was determined by using thin-layer Sephadex G75.

The interpretation of some of these methods has been described (Hobbs, 1966b) and, using them, it is easily possible to distinguish Bence Jones protein in the urine at concentrations of only $1 \mathrm{mg} . / 100 \mathrm{ml}$. from normal light chains in the urine at concentrations of $0.25 \mathrm{mg} . / 100 \mathrm{ml}$.

\section{Biopsy Material}

In some cases where serum and urine results were initially negative, bone marrow or other biopsy fragments (after thrice washing with $4 \%$ human albumin) were inserted into agar and then subjected directly to immunoelectrophoresis. In three patients with undoubted myelomatosis this investigation was negative. In two other patients positive results were obtained, and later confirmed by positive findings in subsequent sera and urine specimens. Hence this method is apparently the most sensitive test available.

\section{Cold Agglutinins}

All patients in whom $\gamma \mathrm{M}$-paraproteins were found were carefully investigated for cold agglutinins. Three patients proved to be suffering from primary cold-agglutinin syndromes and were not included in this study. The remainder did not have appreciable cold agglutinins present in their sera.

\section{Material}

All 146 patients whose initial specimens of sera and urine containing paraproteins were examined between October 1959 and June 1964 are included, together with a further 158 patients studied between June 1964 and March 1965 in whom a diagnosis was possible. The final classification of the patients' conditions was as follows:

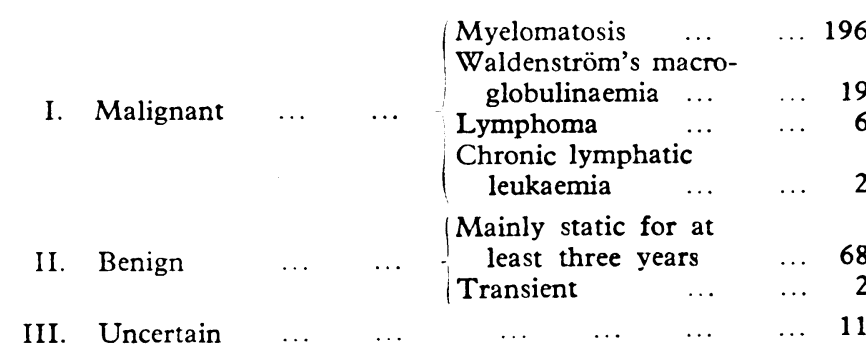

\section{Criteria of Malignancy}

The assumed monoclone was thought to be malignant in 223 patients in whom the following diagnoses were established:

Myelomatosis (196 patients).-(1) Radiological evidence $(87 \%)$-discrete osteolytic lesions $(61 \%)$, diffuse halisteresis with vertebral collapse or pathological fractures in the absence of other known causes (26\%) $(95 \%$ of these patients had a normal serum level of alkaline phosphatase). (2) Biopsy evidence-bone marrow or bone biopsy at operation or necropsy containing an excess of atypical plasma cells which in the opinion of the examining pathologist was characteristic of 
myelomatosis (92\%). (3) Paraprotein detected in serum and/ or urine and/or biopsy ( $\gamma \mathrm{G} 99, \gamma \mathrm{A} 50, \gamma \mu 41, \gamma \mathrm{D} 3)(98.5 \%)$. The diagnosis was never made on a single criterion only: in $78 \%$ all three were present, in the remainder at least two.

Waldenström's Macroglobulinaemia (19 patients).-(1) Severe lassitude with anaemia and neutropenia. (2) Bleeding unaccounted for by thrombocytopenia or a defect of clotting factors. (3) Mild to moderate splenomegaly, slight generalized lymphadenopathy. (4) Biopsy evidence-lymph nodes (architecture well preserved) and/or bone marrow infiltrated with atypical lymphoid cells consistent with the diagnosis in the view of the examining pathologist. (5) Monoclonal $\gamma \mathrm{M}$ globulin eventually greater than 2 g. $/ 100 \mathrm{ml}$.

Features 4 and 5 were found in every case, as were some or all of features 1-3. In eight patients atypical lymphoid cells were also found in the peripheral blood.

Lymphosarcoma (five patients: four $\gamma \mathrm{M}$, one $\gamma \mu$ ); reticulosarcoma (one patient, $\gamma \mathrm{A}$ ).-(1) Massive regional involvement of lymph nodes and/or spleen and/or liver. (2) Biopsy evidence-gross destruction of normal architecture by neoplastic lymphoid or reticulum cells. (3) In four patients unfixed material was studied with fluorescein-conjugated rabbit antisera specific to the heavy chain and light chain of the paraprotein class, which was thereby identified within the cytoplasm of scanty nests of cells within the tumour tissue. In all four cases only $5-15 \%$ of the tumour cells were stained.

Chronic Lymphatic Leukaemia (two patients: one $\gamma \mathrm{G}$, one $\gamma \mu)$.-(1) Peripheral blood lymphocyte counts above 40,000/ cu. $\mathrm{mm}$ for over two years. (2) No evidence of bone lesions or involvement of lymph nodes, spleen, or liver. (3) Only the cytoplasm of a few of the circulating lymphocytes could be stained with fluorescent antibody specific to the paraprotein class.

\section{Criteria of Benignity (68 patients)}

(1) No symptoms related to the presence of paraproteins. (2) No palpable enlargement of lymph nodes, liver, or spleen. (3) Negative radiological survey, including at least the skull and axial skeleton. (4) Bone marrow-apparently normal or with an excess of plasma cells which, however, showed few, if any, atypical features. (5) Followed for at least three years, with no detectable change in the overall picture.

Transient (two patients).-The presence of a $\gamma \mathrm{G}$-paraprotein band was confirmed in the serum of each of these patients on at least three occasions. Nevertheless, the band disappeared within three and six months, and has not reappeared over two and eight years respectively. The first case has been reported in detail (Hobbs, 1966a) and neither is included in Fig. 1.

\section{Uncertain (11 patients)}

These patients had some of the features of malignancynamely, clinical features (5) suggestive radiology (3), suspicious biopsies (7), recurrent infections owing to reduction of other immunoglobulins (4). Nevertheless, in no single patient could all the specialists concerned (physician, haematologist, radiologist, and biochemist) agree about the diagnosis, even by the end of the three-year period of observation-though it was agreed the condition could not be regarded as wholly benign.

\section{Results}

From Fig. 1 it can be seen that if at the initial examination findings (i), (ii), and (iii) were all present a diagnosis of malig- nancy was reached in all 109 patients. From the outset the diagnosis was in doubt in only 10 patients, and in them more definite evidence emerged within eight months. If findings (i), (ii), and (iii) were all absent the outlook appeared benign in all 58 patients three years later. Nevertheless, since this group of patients was selected for follow-up, one exceptional patient has been seen. He was first seen with a pain in the back due to collapse of a single vertebra; on investigation a

Findings No. of potients

\begin{tabular}{|ccccc|c|c|c|}
\hline & & & & & & \\
\hline & & & & & & \\
\hline & & & & & & \\
\hline 57 & 2 & 4 & 9 & 11 & 58 \\
\hline 51 & 1 & 1 & 3 & 0 & 0 \\
\hline 6 & 1 & 1 & 0 & 1 & 0 \\
\hline 0 & 0 & 0 & 0 & 10 & 58 \\
\hline 0 & 0 & 2 & 6 & 0 & 0 \\
\hline \multicolumn{7}{|c|}{$91 \%$} \\
\hline
\end{tabular}

me in 302 patients with paraproteins. Positive findings are shown in Positive findings are shown in black. If (i), (ii), and (iii) were all positive the outcome was malignant in every patient,
whereas if they were all negative the patients appeared to have benign conditions three years later. Between these black and white extremes, positive findings (i) and (ii) had a poor prognosis because $91 \%$ of patients showing these have had malignant conditions. of great value.

$\gamma \mathrm{GK}$-paraprotein $(0.2 \mathrm{~g} . / 100 \mathrm{ml}$.) was detected in the serum, but findings (i) and (ii) were absent. Skeletal survey and bone marrow were negative, but the vertebral biopsy revealed myeloma cells, and two years later there was evidence of recurrence ; the serum paraprotein concentration had risen to $1.2 \mathrm{~g}$./ $100 \mathrm{ml}$., while that of $\gamma \mathrm{M}$ had fallen below normal.

\section{Bence Jones Proteinuria}

This was detected initially in 172 patients (Fig. 1). Of these, 170 have alresdy developed malignant conditions, and this group represents $73 \%$ of the total of 223 malignant cases studied. It must be emphasized that if urine had not been concentrated and thoroughly examined Bence Jones protein would not have been found in 90 patients. Albustix cannot be used for this, while sulphosalicylic acid gave a negative result in 65. Careful layering of cleared urine over concentrated hydrochloric acid (Bradshaw, 1906) has been found to be unsurpassed as a screening test (Hobbs, 1966b), and the presence of a white ring at the junction of the urine and the acid indicated that 162 urines required electrophoresis.

Nevertheless, in the case of six specimens of urine Bence Jones protein was present at concentrations of between 120 and $1,200 \mathrm{mg} . / 100 \mathrm{ml}$. (estimated only after precipitation with ammonium sulphate) but gave negative results with all the screening tests, was not precipitated by $10 \%$ trichloroacetic acid, and was found only by electrophoresis.

The most striking results have been found with the $\gamma \mathrm{M}$ paraproteins. Bence Jones proteinuria was associated with 32 of the 34 malignant cases, though it was present at concentrations of only 1 to $20 \mathrm{mg} . / 100 \mathrm{ml}$. in 26 patients ; in the eight benign cases none was detected.

\section{Other Immunoglobulins}

Subnormal serum levels of one or more of the immunoglobulins of classes other than that of the paraprotein were found initially in 227 patients, and of these 218 proved to have malignant disease. Only five of 223 patients with malignant conditions had normal levels.

In $\gamma \mathrm{G}$-myelomatosis subnormal levels of $\gamma \mathrm{M}$ - and $\gamma \mathrm{A}$-protein were found to be the rule ( 86 out of 99 patients) ; seven patients 
had a concentration of $\gamma \mathrm{M}$ within normal limits, seven had a normal $\gamma \mathrm{A}$ level, but only one patient had both normal $\gamma \mathrm{M}$ and $\gamma \mathrm{A}$. Among 53 patients with $\gamma \mathrm{A}$ or $\gamma \mathrm{D}$-myelomatosis, the level of $\gamma \mathrm{M}$ was subnormal in 44 and of $\gamma \mathrm{G}$ in 42, and only one patient had normal levels of both $\gamma \mathrm{M}$ and $\gamma \mathrm{G}$. In myeloma producing Bence Jones protein only, the $\gamma \mathrm{M}$ level was subnormal in 40 out of 41 patients: normal levels of $\gamma \mathrm{G}$ and $\gamma \mathrm{A}$ were found initially in 10 and 9 patients, respectively, but only one patient had concentrations of all three within normal limits. All three patients with undoubted myelomatosis, in whom no paraprotein could be detected, showed subnormal levels of immunoglobulins. Thus among 196 patients who developed myelomatosis only three had normal levels of the other immunoglobulins when first seen. For each immunoglobulin taken separately these results are very similar to those reported by Bachmann (1966), who, however, does not state whether the few patients with normal $\gamma \mathrm{A}$ also had normal levels of $\gamma \mathrm{M}$ and other proteins.

Of the first 19 patients seen with Waldenström's macroglobulinaemia, two had normal levels of the other immunoglobulins. Among the total of 34 malignant $\gamma \mathrm{M}$-paraproteinaemia (Fig. 2) the levels of $\gamma \mathrm{G}$ and $\gamma \mathrm{A}$ were within normal limits in 16 and 10 , respectively, though only six patients had normal levels of both $\gamma \mathrm{G}$ and $\gamma \mathrm{A}$.

In Fig. 2 it can be seen that, though the concentration of the other immunoglobulins tends to decrease as the daily production of paraprotein increases, the presence of $\gamma \mathrm{G}$-paraproteins is associated with the most severe reduction (even less than $10 \%$ with daily paraprotein productions below $10 \mathrm{~g}$.). The reduction is not so severe with higher daily productions of $\gamma \mathrm{A}$, $\gamma \mathrm{M}$, and Bence Jones paraproteins. This reduction was especially associated with the malignant group, for the concentrations of the other immunoglobulins, though sometimes at the lower limits, have remained within normal limits in 68 patients in the benign group.

\section{Levels of Serum Paraproteins}

Apart from the 45 patients who produced only Bence Jones proteins, 175 patients with serum paraproteins were diagnosed as having malignant conditions, $161(92 \%)$ of whom had levels greater than $1 \mathrm{~g} . / 100 \mathrm{ml}$. when first seen. This contrasts with the 68 patients whose conditions were regarded as benign, 58 $(85 \%)$ of whom had levels of less than $1 \mathrm{~g} . / 100 \mathrm{ml}$.

\section{Progress in Doubtful Cases}

Of the 304 patients there were 110 in whom a firm diagnosis could not be reached initially. In these the paraprotein estimations were repeated at 3 - to 12 -monthly intervals. Within three years malignant conditions had developed in 29 patients, all of whom showed a significant $(>0.2 \mathrm{~g} . / 100 \mathrm{ml}$.) and rapid . increase in paraprotein level. In most cases only a second or third measurement was obtained before treatment was begun.
Results in the patients who were followed the longest-and who clearly developed the bone lesions of myelomatosis-are shown in Fig. 3. By plotting the paraprotein level on a logarithmic scale against time on a linear scale, it can be seen that the rate of increase is exponential or only slightly curved: the doublingtime ranges from 4 to 25 months. This closely agrees with the data of Hällén (1966), many of whose 23 patients have had a longer follow-up: most of these showed exponential increases, and in 17 it was possible to estimate the doubling-time. Com-

FIG, 2-Reduction of normal serum immunoglobulins in relation to paraprotein production in patients ( $\mu$, mostly without renal failure when first seen) present with lower production rates than the others, sarcoma. (Open symbols indicate 11 additional patients $(\gamma M)$ not in the consecutive series.)
saling derentiation of their tumours. Wyelomatosis.

bining his results with the above nine, one obtains a median doubling-time of 12 months. The limit of likely detection of a serum paraprotein on cellulose acetate is about $0.2 \mathrm{~g} . / 100 \mathrm{ml}$. Average serum levels of paraprotein at the time of clinical presentation and diagnosis are $\gamma \mathrm{G} 4.3 \mathrm{~g} . / 100 \mathrm{ml}$. and $\gamma \mathrm{A}$

NUMBERS = DOUBL INC TIME IN MONTHS

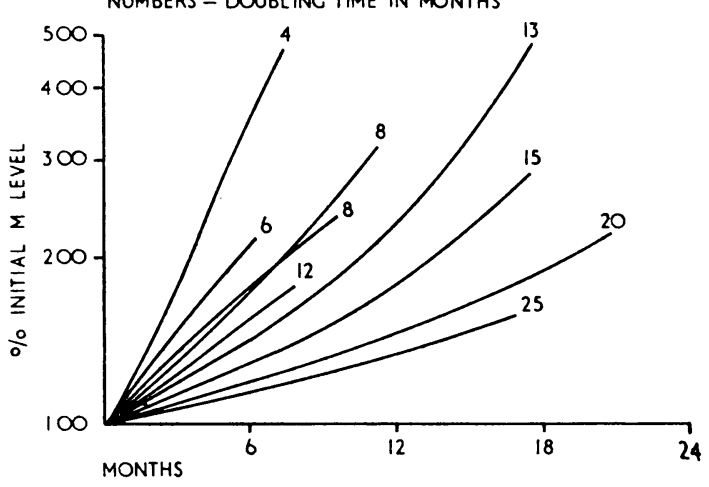

FIG. 3.-Progress in nine untreated patients in whom a diagnosis of myelomatosis was later established. The increasing serum paraprotein (M) level is shown on a creasing serum paraprotein (M) least four points on logarithme scale; there were at least four points on each line. The increase is exponential (straight line) or nearly so, enabling estimation of the doubling times in months as indicated above. 
2.8 g. $/ 100 \mathrm{ml}$. (Hobbs et al., 1966). Thus an exponential increase from the earliest serum level of chance detection to the average level when clinical diagnosis is certain could take between 18 months and nine years for $\gamma \mathrm{G}$ and between 15 months and eight years for $\gamma \mathrm{A}$ myelomatosis. Nevertheless, most patients will show significant increases $(>0.2 \mathrm{~g} . / 100 \mathrm{ml}$.) in these levels within two years.

In contrast, 66 of the 68 patients classified as having benign conditions have not shown any persistent significant increase over three years. Two have shown increases (1.3 to 2.0 and 1.4 to 1.8 over three years). This finding again agrees well with that of Hällén.

\section{Discussion}

The natural frequency of the occurrence of serum paraproteins has been reported by Axelsson et al. (1966). Out of a population of $6,995,64$ subjects showed $M$ proteins, and a malignant condition was at that time suspected in only four. Routine electrophoresis of serum obtained from 7,200 new patients at Hammersmith Hospital between December 1963 and June 1964 revealed the existence of 55 paraproteins. After three years' follow-up only $40 \%$ of these patients can be considered to have benign conditions, a malignant condition having been diagnosed in $53 \%$ and the diagnosis being uncertain in $7 \%$.

From the results it can be seen that Bence Jones proteinuria in excess of $1 \mathrm{mg} . / 100 \mathrm{ml}$. is of sinister significance. Of the normal daily production of $5 \mathrm{~g}$. of immunoglobulin (Fahey, $1965)$ only $3.5 \mathrm{mg}$. (0.07\%) appears as normal light chains in the urine, in a concentration of about $0.25 \mathrm{mg} . / 100 \mathrm{ml}$. (Berggard and Edelman, 1963). Thus an increase in lightchain excretion reflects an inefficient process and probably implies that the synthesizing cells have lost their differentiation. The production of Bence Jones protein indicates further dedifferentiation and the prognosis is worse. These patients present with lower daily paraprotein production rates than those for the other classes (see Fig. 2), and most are dead within six months of diagnosis, though one exceptional patient who survived 15 years has been seen.

The other feature signifying an adverse prognosis is the loss of normal immunoglobulins, originally emphasized by Grabar et al. (1956). In four patients a severe reduction in immunoglobulin levels was detected one to three years before the malignant clone was large enough to produce detectable lesions or paraproteins (premyelomatosis).

The mechanism of the suppression of immunoglobulin production remains unknown. Displacement of normal antibodyproducing cells seems unlikely; indeed, the production of $\gamma \mathrm{A}$ globulin-which is derived largely from the gut-may be severely reduced with no regional involvement of the gut. The presence of an excess of $\gamma \mathrm{G}$-paraprotein resulted in an increased turnover and a reduced level of normal $\gamma \mathrm{G}$-globulins in six out of the 11 patients studied by Solomon et al. (1963). Nevertheless, turnover of $\gamma \mathrm{M}$-glabulin has not been shown to be affected (Barth et al., 1964), so that increased catabolism cannot account for the usual severe reduction of $\gamma \mathrm{M}$-globulin levels. It seems probable that the synthesis of $\gamma \mathrm{M}$-globulin is impaired, as is that of $\gamma \mathrm{A}$-globulin. In two patients removal of an apparently solitary myeloma was found to restore the levels to normal (Hobbs, 1966a), and this suggests that the tumours release some humoral substance which inhibits the synthesis of normal immunoglobulins but not that of paraproteins.

Nathans et al. (1958)-confirmed by Osserman et al. (1964) -found that in mice there was a linear relation between the amount of plasmacytoma and the serum level of $\gamma$-paraprotein -which was produced at a daily rate of about $14 \mathrm{mg}$. $/ \mathrm{g}$. welldifferentiated tumour. This roughly agrees with the estimated rate of production of antibody by single cells (Nossal and Mäkelä, 1962). On average, patients with $\gamma \mathrm{G}$-myeloma have a serum level of this paraprotein of $4.3 \mathrm{~g} . / 100 \mathrm{ml}$. when first seen, and produce some $13 \mathrm{~g}$. of paraprotein daily. This total production could require $930 \mathrm{~g}$. of tumour to be present. Harrison (1962) estimated that for a 70-kg. man the total bonemarrow cellularity was $7.5 \times 10^{11}$ cells. If the haemopoietic tissue is assumed to weigh a total of $1,625 \mathrm{~g}$., each $1 \mathrm{~g}$. would contain $4.6 \times 10^{8}$ cells, and $930 \mathrm{~g}$. of $\gamma \mathrm{G}$-myeloma tissue could contain $4.3 \times 10^{11}$ cells. The average $60-\mathrm{kg}$. man would have a bone marrow of $3,250 \mathrm{~g}$. (Mechanik, 1926). Normally about

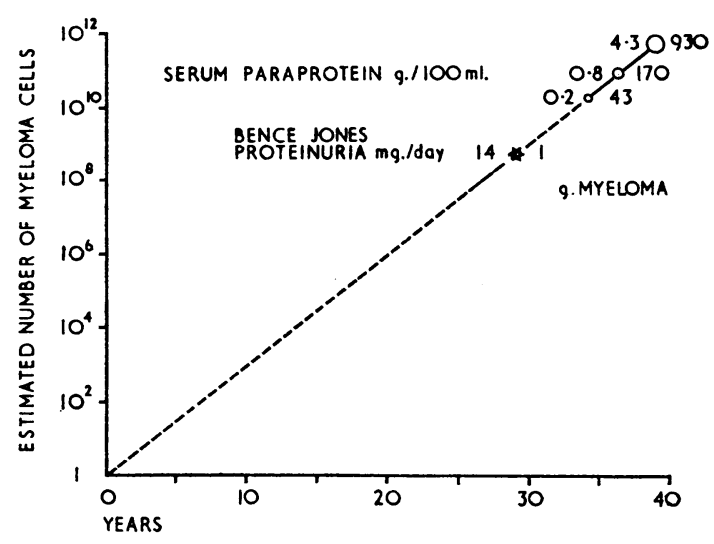

FIG. 4.-Schematic development of myelomatosis. The solid part of the line shows the observed exponential increase of serum paraprotein level from the lowest detectable level of 0.2 to the average level of $4.3 \mathrm{~g} . /$ $100 \mathrm{ml}$. found in patients presenting with $\gamma \mathrm{G}-$ myelomatosis. At the median doubling-time of 12 months matosis. At the median doubling-time of 12 months this would take about five years. The star indicates the earliest possible detection of myeloma 10.7 years before the usual time at this doubling rate. If it is assumed that the serum level reflects the myeloma mass and its contained cells, the extrapolated broken line shows that if it arose from a single cell and grew at the same exponential rate throughout it began some 39 years previously.

half is haemopoietic. Patients with $\gamma \mathrm{G}$ myeloma have on average $42 \%$ myeloma cells in bone marrow biopsies-that is, $685 \mathrm{~g}$. if half the marrow is haemopoietic or $1,370 \mathrm{~g}$. if the marrow is fully occupied. The independent estimate is similar to that based on paraprotein production. If the myeloma tissue is a clone derived from a single cell then it would take almost 39 doubling divisions to reach this number of surviving cells. If we now accept, in man as in the mouse, that the doublingtimes of paraprotein levels (4-25 months, Fig. 3) reflect the doubling-times of the cells producing them, it could take 13 to 80 years before the amount of $\gamma \mathrm{G}$-myeloma was sufficient to produce symptoms.

Hence chance detection of a serum paraprotein might not occur for 11 to 70 years (see Results) -though an isolated lesion, such as the collapse of one vertebra or the finding of Bence Jones proteinuria, could reveal the presence of an early myeloma, which might then take up to 20 years to declare itself clinically. These conclusions are summarized in Fig. 4 for a median doubling-time of 12 months: the dotted portion of the line is speculation based on results in the mouse. Similar extrapolations have offered accurate explanations for the latent periods observed between irradiation of humans and the subsequent clinical emergence of acute leukaemia and thyroid cancer (reviewed by Hobbs, 1963).

Such estimates assume that the growth of the cells is exponential throughout, and this is not always the case. Some tumours outgrow their blood supply and undergo necrosis, but myeloma is well placed to avoid this, though a change in growth rate has been seen in two patients. Furthermore, these estimates apply only to well-differentiated tumours, in which virtually all the neoplastic cells eventually produce paraprotein. Our own experience with fluorescent antisera suggests this is so in most cases of myelomatosis, though in the mouse Osserman 
et al. (1964) found that after multiple passages the cells comprising the plasmacytoma could become considerably less differentiated, producing less paraprotein and growing faster. A few patients with obviously extensive rapidly growing myeloma similarly produce little or even no paraprotein, especially those who produce only Bence Jones protein.

In lymphosarcomata and in chronic lymphatic leukaemia, on the other hand, it seems to be the rule that when paraprotein production occurs it involves only a small percentage of the tumour cells. Mackay et al. (1957) thought that the presence of macroglobulinaemia in such cases was a secondary phenomenon, and arose from a side-line of mutated cells. The presence of more than one paraprotein has been demonstrated in three of our six patients with lymphomata-an incidence that is in marked contrast to our findings in myelomatosis, five out of a total of 320 patients showing more than one paraprotein. These findings also agree with those of Imhof et al. (1966), and support the hypothesis that paraprotein production in the tymphomata reflects unstable, mutating cell populations.

Paraproteins are also found in association with other malignant diseases, but their frequency is no greater than would be expected (Hällén, 1966). Moreover, their levels rarely correlate with the removal or progress of the cancer, and our own experience suggests that this largely occurs by chance.

\section{Summary}

Examination of blood and concentrated specimens of urine for paraproteins, together with the measurement of the other immunoglobulins, can have prognostic value in some groups of patients. In doubtful cases, following the paraprotein level can indicate within one to three years which cases are likely to show malignancy, though up to 10 years may be required before the diagnosis is certain, and up to 20 years where solitary lesions or only a trace of Bence Jones proteinuria are the presenting features.
This article would have been impossible without the participation and encouragement of the Medical Research Council and its Myeloma Trial Working-party. Many other patients have been referred from other physicians, particularly my colleagues at Hammersmith, who have kindly provided fuil details and follow-up data. I am indebted to the staff of the haematology and radiological departments. I would also like to thank Professor I. D. P. Wootton, Professor J. V. Dacie, and Dr. D. A. G. Galton for their guidance; Miss Hazel Gardner, Miss Susan Burtenshaw, and Mrs. Ann Kasler for their assistance; and Mr. K. B. Cooke for early guidance in immunoelectrophoresis.

\section{REFERENCES}

Axelsson, U., Bachmann, R., and Hällén, J. (1966). Acta med. scand., 179,235 .

Bachmar. (1966) Scand. 7. ciin. Lab. Invest., 18, 273 and 280.

Bachmann. R. (1966). Scand. F. ciin. Lab. Invest., 18, 273 and 280. (1964). $\ddot{f}$. clin. Invest., 43, 1036.

Eerggard, I., and Edelman, G. M. (1963). Proc. nat. Acad. Sci. (Wash.), 49,330 .

Bradshaw, T. R. (1906). Brit. med. F., 2, 1442

Drivsholm. A. (1964). Acta med. scand., 176, 257.

Fahey, J. L. (1965). F. Amer. med. Ass., 194, 255.

Gabuzda, T. G. (1962) 7. Lab. clin. Med. 59, 65.

Grabar, P. Fauvert, R., Burtin, P. and Hartmann, L. (1956). Rev franc. Etud. clin. biol., 1, 175 .

Hällén, J. (1966). Acta med. scand., Suppl. No. 462

Harrison, W. J. (1962). 尹. clin. Path., 15, 254

Harrison, W. J. (1962) M. Clin. Path., 15, 254. 15.

Hobbs, J. R. (1963). M.D. Thesis, Lond

- (1965). Nature (Lond.), 207, 292. (1966b). Biochem. 7., 99, 15P. and Maatela, J. (1967). To be published.

- ct al. (1966). Lancet, 2, 614.

Imhof, J. W., Ballieux, R. E., Mul, N. A. J., and Poen, H. (1966). Acta med. scand., Suppl. No. 445 , p. 102.

Lowry O. H. and Hunter, T. H. (1945). F. biol. Chem., 159, 465.

MacKay, I. R., Taft, L. I., and Woods, E. F. (1957). Brit. med. F., 1 561 .

Mechanik, N. (1926). Z. ges. Anat., 79, 58.

Nathans, D., Fahey, J. L., and Potter, M. (1958). 7. exp. Med., 108, 121

Nossal, G. J. V., and Mäkelä, O. (1962). Ann. Rev. Microbiol., 16, 53. Olesen, H. (1963). Scand. F. clin. Lab. Invest., 15, 497.

Osserman E. F., Rifkind, R. A., Takatsuki, K., and Lawlor, D. P. (1964). Ann. N.Y. Acad. Sci., 113, 627.

Solomon A. Waldmann, T. A., and Fahey, J. L. (1963). J. Lab. clin. Med., 62, 1.

\title{
Lymphocyte Transformation and Chromosome Studies in Hodgkin's Disease
}

\author{
SYLVIA D. LAWLER,* M.D., M.C.PATH. ; C. R. PENTYCROSS, † M.B., B.CH. ; B. R. REEVES,
}

Brit. med. F., 1967, 3, 704-708

The circulating lymphocytes in Hodgkin's disease are assumed to be immunologically deficient because of the poor response shown by the patients in delayed hypersensitivity tests. There is some evidence that this anergy is present even in the earliest stages of the disease (Aisenberg, 1965). The question therefore arises whether the lymphocytes are also abnormal in any other respect.

One way of testing a population of lymphocytes is to study the responses to stimulation in vitro by phytohaemagglutinin. When normal lymphocytes are cultured with phytohaemagglutinin a high proportion are stimulated to divide, and a cell showing the associated morphological changes is said to have "transformed." Recent studies (Hersh and Oppenheim, 1965) have shown that the response of the lymphocytes in Hodgkin's disease is sometimes depressed. At least three factors may influence the response: the lymphocyte count, which is often very low; the stage of the disease at the time of investigation;

* Senior Lecturer.

+ Leukaemia Research Fellow.

$¥$ Research Assistant.

Department of Clinical Research, Royal Marsden Hospital and Institute of Cancer Research, London S.W.3. and the effects attributable to radiation or chemotherapy. We have attempted to assess the relative importance of these factors.

Another way of characterizing a cell population is to determine the chromosome complement. Apart from a single case of Spiers and Baikie (1966), in which the peripheral blood lymphocytes were found to be normal, no information about the chromosomes of the circulating lymphocyte in Hodgkin's disease is available. There is no doubt that chromosomal abnormalities are detectable in lymph node material (Ricci et al., 1962; Spriggs and Boddington, 1962 ; Galan et al., 1963 ; Baker and Atkin, 1965 ; Miles et al., 1966 ; Spiers and Baikie, 1966). Various abnormalities have been described, including polyploid cells, presumed to represent SternbergReed cells, and anomalous chromosomes, particularly of the $\mathrm{E}$ group, in diploid cells.

\section{Materials and Methods}

Twenty cases have been studied. Some of the patients are the same as those investigated by Goldman and Hobbs (1967). The method used in the lymphocyte transformation tests is that 